\title{
Teaching Sustainable Development in a Sensory and Artful Way-Concepts, Methods, and Examples
}

\author{
Harald Heinrichs
}

check for updates

Citation: Heinrichs, H. Teaching Sustainable Development in a Sensory and Artful Way-Concepts, Methods, and Examples. Sustainability 2021, 13, 13619. https:// doi.org/10.3390/su132413619

Academic Editors: Dunja Anđić, Nena Rončević and Michele Biasutti

Received: 14 October 2021

Accepted: 6 December 2021

Published: 9 December 2021

Publisher's Note: MDPI stays neutral with regard to jurisdictional claims in published maps and institutional affiliations.

Copyright: (C) 2021 by the author. Licensee MDPI, Basel, Switzerland. This article is an open access article distributed under the terms and conditions of the Creative Commons Attribution (CC BY) license (https:/ / creativecommons.org/licenses/by/ $4.0 /)$.
Institute of Sustainability Governance, Leuphana University Lüneburg, 21335 Lüneburg, Germany; harald.heinrichs@leuphana.de

\begin{abstract}
Despite significant short-term pressures such as the recent Coronavirus pandemic with its economic and social disruptions, longer-term environmental un-sustainability and its projected intergenerational consequences remain a major threat for the future of mankind. More and new efforts are required in all social spheres with regard to the universal Sustainable Development Goals. In this context, the present article makes the argument for teaching sustainable development in higher education with a more sensory and artful approach, in order to raise students' awareness of the multisensory reality of human existence and develop skills to engage creatively for sustainability transformations. Rooted in the perspective of sensory and arts-based sustainability science, three experimental bachelor courses-designed and conducted by the author of this article in collaboration with artists-with twenty to twenty-five students in each course from diverse disciplinary backgrounds in environmental studies, cultural studies, and social sciences are presented and discussed. It is argued that the specific course design and the scientific-artistic co-teaching provide an innovative way to teach sustainability topics in a more sensory way. The article ends with an outlook on potentials and challenges of this approach.
\end{abstract}

Keywords: education for sustainable development; sensory sustainability science; arts-based research and teaching

\section{Introduction}

The Coronavirus pandemic has shaken the world at the beginning of the new decade. Like other major crises, the pandemic has revealed weaknesses not only in health systems, but of state functioning, economic resilience, and social cohesion around the world. The complicated coping of short- and long-term concerns is even more difficult in the face of political turmoil, such as ongoing populist and authoritarian pressures on democratic policy making or international upheavals such as Brexit or the US-China trade conflict. Within this complicated landscape of issues and actors, the UN-Transformation Agenda 2030 with its global sustainability goals (SDG's) nevertheless remains the central reference point of the international community [1]. Even though the international adoption of the Agenda in 2015 has not led to substantial improvements towards sustainable development, until today, the sheer existence of the SDG's and its monitoring helps to remind the international community that more and new efforts on sustainable development are required in all social spheres [2]. In this regard, the present article focuses on education (SDG goal 4). It makes a plea for teaching sustainable development in a more sensory and artful way in order to reflect more systematically the multisensory reality of human existence and support skills for creative and imaginative engagement in transformative sustainability interventions. Based on the perspective of sensory sustainability science [3], which employs theoretical considerations of interdisciplinary sensory studies and methodological approaches of sensory ethnography and arts-based research, this article reflects on three experimental courses that took place over the past three years at the Leuphana University Lüneburg (www.leuphana.de, 14 October 2021) in Germany. It aims at proposing how arts-based 
and sensory sustainability science can be operationalized in (higher) education courses. The article ends with a reflection on potentials and challenges of this approach for teaching sustainable development in (higher) education and the need for evaluative research of controlled experiments in the future.

\section{2. (Un)Sensory Sustainability Science}

The guiding vision of sustainable development represents a global scientific-analytical, ethical-normative, political-ideological, as well as practical-behavioral phenomena. Sciences for sustainable development provide a wide spectrum of knowledge and solution options based in conceptual and empirical findings and modeled future projections [4]. The scientific insights are closely related to ethical-normative discourses such as on intraand intergenerational justice or human-nature relationships. Scientific-analytical and ethical-normative perspectives are employed by political-ideological positions, for example, regarding sustainability strategies ranging from sustainable capitalism to eco-socialism or the role of regulatory vs. market-oriented approaches [5,6]; and last but not least, science-based options materialize in concrete practical-behavioral everyday performances of people in their different social roles as political, economic, civic, and private actors [7]. This complexity of sustainable development as multi-actor, multi-sector, multi-topic, and multi-level issue led to the emergence of sustainability science over the past two decades. Rooted in pioneering activities of interdisciplinary environmental sciences multi-, inter, and transdisciplinary sustainability science aims at providing an adequate scientific way of contributing to the multifaceted challenge [8]. Sustainability science strives to deal proactively with the intermingled scientific-analytical, ethical-normative, politicalideological, and practical-behavioral dimensions of sustainable development [9]. Based on well-established knowledge on unsustainable developments, sustainability science aims at supporting transformation processes towards sustainable development through co-creation between scientific and societal actors and by emphasizing a strong solution-orientation [10]. These conceptual, methodological, and epistemological innovations, which lead in particular to a reflected consideration of heterogeneous forms of knowledge, values, norms, and interests, follow generally a cognitivistic model rooted in terminological thinking and argumentative deliberation in order to fulfill fundamental institutional requirements and expectations of science. Compared with this, the multisensorial reality of humans as sensing corporeal beings influenced by pre-verbal sensory experiences and embodied imaginations is addressed less explicitly [11]. In the light of social scientific theories and methods specialized on researching the multisensoriality of humans, sustainability science seems to be largely un-sensory [3].

(This section is based on prior elaborations on the topic: Heinrichs (2019a, 2019b)) Great thinkers such as Karl Marx (1989) [12], Sigmund Freud (2009) [13], Georg Simmel (1907) [14], Helmut Plessner (1980) [15], or Maurice Merleau-Ponty (1965) [16] have reflected on the fundamental role of sensory experiences, corporeality, affect, emotions, and embodied imagination for everyday life. With varying foci, they (re-)conceptualized humans as bodily subjects in socio-material worlds, emphasizing the cognitive and corporeal co-construction of sense-making, the corporal-sensorial (co-)presence of humans and non-humans as well as the interplay of mind and body, sensing and interpreting, and intuition and conception. Building on these pioneering works, the interdisciplinary field of sensory studies has generated over the past two decades an impressive body of knowledge on the role of the senses in human life and how the multisensorial reality of social practices is shaped by culturally mediated multisensorial conditions and experiences [11]. Of specific interest in the present context, are philosophical and sociological approaches, which conceptualize the relational effects between humans and non-humans, the material world of objects and the inner world of subjects. Of particular relevance in this regard are three theoretical lines of thinking: (1) The idea of atmosphere, understood as co-processed phenomena between sensing (human) subjects and mood-carrying material and social worlds, ranging from pristine nature, to crowded noisy streets up to funerals or sport 
events [17]. (2) The practice theory exploring the implicit informal logic of social life driven by routinized social practices based on unreflected embodied knowledge and imagination and its practical corporal doing in concrete socio-material situations such as mobility behavior, physical labor, or bodily expression in culturally preformed social interactions [18,19]. (3) Finally, the theory of resonance, which employs corporeal, sensory, and material perspectives to argue that humans are anthropologically oriented towards resonance, which is defined as emotional and corporeal-affective sensed forms of reverberations of lived experiences that go beyond those available to abstract cognitive-interpretative perception and evaluation [20]. Resonant relationships can be found where humans actively engage as mental-corporeal beings, driven by intrinsic interest and self-efficacy expectations with an openness to being touched by the world's own voice: whether in gardening, playing sports or an instrument, interacting reciprocally with family, friends, or colleagues, or fulfilling a sense-making occupational task. All these theories emphasize the need to go beyond a reductionist view of cognitive-interpretative sense-making of the world and address more systematically sensory-affective ways of sense-making in its own right.

For the exploration of multisensorial dimensions, two methodological approaches can be considered as particularly promising: sensory ethnography and arts-based research. Rooted in the qualitative, explorative, participatory, and interpretative style of doing ethnographic research by employing narrative interviews, observation, photography, or audio-visual recording, the approach of sensory ethnography has been developed over the past two decades [21]. The multisensoriality of human life is put at the center of interest and it is analyzed how the different senses-smell, taste, visual, audio, touch, and kinesthetic-are interconnected with fundamental aspects of human existence such as perception, place, knowing, memory, or imagination. Within this emerging field of research, new methods have been explored as well including autoethnography, interventionist ethnography, participatory audio-visual recording, up to imaginative practices such as fictional ethnographic writing and others [22]. Closely related to the way of doing sensory ethnography is the field of arts-based research. Arts-based research covers creative research practices, which aim at alternative ways of knowledge production and communication beyond established quantitative and qualitative scientific methodologies [23]. The epistemic core is oriented towards scientific-aesthetic knowing. Aesthetics, understood as sensory perception and intuition, shall complement and enrich scientific inquiry by methods such narrative inquiry, fiction-based research, poetry, music, dance, theatre, film, and visual art. Arts-based research allows for an alternative way of understanding and interpreting reality by revealing multiple meanings of phenomena, raise empathetic awareness, and stimulate imagination for transformative practices. Patricia Leavy has summarized the differences between quantitative, qualitative, and arts-based methods, and - thereby - she points out the complementary potential for scientific-aesthetic knowledge generation (Table 1):

Table 1. Specificities of arts-based methods compared to quantitative and qualitative methods [23].

\begin{tabular}{|c|c|c|}
\hline Quantitative & Qualitative & Arts-Based \\
\hline numbers & words & stories, images, sounds, scenes, other sensory inputs \\
\hline data discovery & data collection & data or content generation \\
\hline measurement & meaning & evocation \\
\hline tabulating & writing & (re)presention \\
\hline value neutrality & value non-neutrality & political/emancipatory consciousness \\
\hline reliability & process & authenticity \\
\hline validity & interpretation & truthfulness \\
\hline proof & persuasion & compelling/moving/aesthetic power \\
\hline generalizability & transferability & resonance \\
\hline disciplinarity & interdisciplinarity & transdisciplinarity \\
\hline
\end{tabular}

Although sensory ethnography and arts-based research are relatively young social scientific practices, one can find a few pioneering studies which employ these approaches for sustainability issues such as "sensecapes" in the slow city movement or on the value 
of arts-based research for strengthening imaginary and transformative potentials [24-26]. These conceptual, methodological, and pioneering empirical attempts are the building blocks for a more sensory and aesthetic sustainability science [3,27]. In this line of thinking, it is argued that multisensoriality, corporeality, and embodied cognition and imagination for human (inter)action in material and social worlds are especially of relevance for transformative processes towards sustainable development. These perspectives serve as a starting point and orienting conceptual background for the design of experimental courses, which aim at addressing the multisensory reality of human existence more adequately. Through such an approach, students may gain new insights, ideas, and acquire skills to study and shape sustainable development sensory and artfully in their future professional and private lives. Before three exemplary courses are presented, (un)sensory approaches in (higher) education for sustainable development are reflected in the next section.

\section{3. (Un)Sensory Approaches in (Higher) Education for Sustainable Development}

Education for sustainable development (ESD) has emerged in the past three decades and is today a widespread global phenomena [28-31]. One can find uncountable initiatives, approaches, and institutionalizations in formal education in primary, secondary, and tertiary education, as well as informal educational settings such as in socio-cultural centers. Rooted in preceding and neighboring fields such as environmental education, intercultural education, or global learning, ESD has been conceptually and methodologically developed and diffused in the context of the UN world programs on sustainable development, namely the Agenda 21 (1992-2015) [32], the Transformation Agenda 2030 [1], and the related strategies of the UN Decade of Education for Sustainable Development (2005-2014) [33] and the Global Action Program led by the UNESCO (2015-2019) [34]. ESD is now internationally recognized as key issue by its incorporation in the global sustainable development goals (Goal 4). Despite its wide fields of application, from kindergarten to university, from schools to environmental education centers, and its broad spectrum of sustainability topics, from climate change to biodiversity, social inequality to sustainable consumption, ESD is defined by some principles and ways of working. The UNESCO indicates five central dimensions: learning content (integrating critical issues), pedagogy and learning environments (learnercentered and action oriented), societal transformation (transform themselves and society), and learning outcomes (core competencies) [35].

This praxis-oriented promotion of ESD principles is backed by a differentiated conceptual and methodological discourse, which keeps on going to reflect on ESD and elaborate it further. Despite slight differences in approaches and arguments, a broad agreement on several aspects can be observed. Firstly, it can be stated that ESD is not only about introducing new topics—such as climate change-into traditional education formats and structures, focusing on knowledge transfer in an instrumental understanding of raising awareness. In contrast, it argues for a much deeper realignment of institutional contexts, curricula, and didacticism: the focus has shifted from instrumental to emancipatory education, a more learner-centered teaching style is propagated as is an inter- and transdisciplinary, real-world problem and solution orientation, crossing boundaries of school subjects and disciplines and-last not least—strong emphasis is given to competence development [36,37]. Even though some differing exists between authors and schools, a range of key competencies can be seen as essential to ESD [38]: systems thinking, anticipatory competence, normative competence, strategic competence, and interpersonal competence. In order to develop these competences and abilities, experiential learning, which allows for integrating and experiencing different learning dimensions, is considered of key relevance [39,40]. In this perspective, ESD aims at training upcoming generations to be capable, and be able to, competently reflect and contribute in private and professional life to sustainable development. In this regard ESD represents a transformative understanding of and by education. However, despite all the important conceptual and methodological innovations in ESD, it remains dominantly oriented towards cognitivist, terminological thinking for analyzing sustainability problems and developing solution options. The more recent "sensory 
turn" in social sciences has not been systematically considered [11]. Sensory dimensions are not prominently mentioned either in the programmatic description of the UNESCO nor in the widely discussed key competencies. Nevertheless, one can find-especially more recently-studies discussing the potentially supporting role of arts for education on sustainable development. These studies can be grouped into three lines of thinking. On the one hand, the contribution of arts in education for sustainable development is looked at through the lens of cultural sustainability. Sustainability is considered in this context fundamentally as a cultural challenge and the arts are introduced as a way to enable a kind of "aesthetic learning" [25]. On the other hand, there are publications that discuss the particular potential of specific art forms-such as music or drama-in sustainability education, oftentimes with a focus on early childhood and schools [41-46]. Finally—and most recently-more comprehensive publications on arts, education, and teaching have been published [47-49]. The capabilities of arts and arts-based education are elaborated and a broad spectrum of approaches is presented. Looking at three decades of education for sustainable development, it can be stated that sensory-aesthetic dimensions of sustainable development have not been taken center stage in most conceptualizations. Most notably, higher education for sustainable development appears to be largely un-sensory. From the perspective of sensory sustainability science and looking at the recent publications on arts for sustainability education, it seems to be the right time for integrating more systematic sensory and arts-based approaches into (higher) education for sustainable development. Based on this viewpoint exemplary, experimental courses will be presented and discussed in the next section.

\section{Teaching Sustainable Development Sensory and Artfully-Examples and Experiences}

Between 2017 and 2020, three experimental courses were conducted at the Leuphana University, Lüneburg, Germany, with the aim of exposing students to sensory-aesthetic approaches and experiences in studying sustainable development. The courses were part of the complementary studies stream in the undergraduate program. In this stream, courses are open for students from all study programs. The courses were based on the conceptual and methodological perspective of sensory sustainability science as discussed above. Thus, theoretical ideas of interdisciplinary sensory studies and methods of sensory ethnography and arts-based research and teaching were employed for designing and conducting the courses. In order to professionally address the sensory-aesthetic dimension, the courses took place in cooperation with, and co-teaching by, specialized artists for each course. The role of the sustainability scientist, the author of this article, was to bring in the conceptual and methodological perspective of sensory sustainability science. The role of the artist was to contribute the respective artistic practice and support the students in developing and conducting the artistic-aesthetic parts of their projects. Throughout the seminars, scientist and artist were present and engaged in collaborative co-teaching. Thus, scientific and artistic perspectives were continuously interconnected with each other. In the following, the courses are at first individually presented. The central aim of the course, the underlying idea, as well as the organizational and content-related structure will be outlined. Then, the collaboration with the participating artists in the seminar, as well as the operational realization of the course, is described and reflected upon. Even though this study focuses on providing design options for teaching sensory and arts-based sustainability science, and it is not aimed at measuring learning impacts, impressions from discursive feedback given by students in the course are cursorily mentioned. Thereafter, the overarching experiences are discussed and key insights are derived. Thus, a descriptive analysis in the sense of dense description of curriculum design and conduct is aimed at, how arts-based and sensory teaching for sustainable development can be operationalized in (higher education) courses. Thereby, the article wants to provide a praxis-oriented innovative impulse for curriculum development. It is not designed as, nor meant to be, a student-centered evaluative impact study of a controlled experiment. 


\section{Case Study 1: Sustainability, Politics, Everyday Life}

In the winter term 2017/18, the seminar "Sustainability, Everyday Life and Politics" (all courses took place in German. Aim, content, and structure have been translated into English for this article.) was offered. The course aimed at employing the approach of visual ethnography for exploring the materialization of politically contested issues of (un)sustainability in everyday life and practice. By the means of an audio-visual knowledge production, communication skills beyond that of a text- and data-based scientific analysis should be encouraged, and a reflection of sensory dimensions of sustainable development enabled. The underlying idea for this experiment in teaching sensory sustainability science were threefold: firstly, the observation that the widespread digitalization increases the phenomena of "visual societies" [50]. Secondly, the leaps in digital information and communication technologies, such as camcorder or smartphone, allow for the production of videos of good quality with limited technical skills. Thirdly, the research practice of visual ethnography, which builds on early explorations with photography in ethnology, has been elaborated in the past decades as a method for producing and communicating sensory ethnographic insights [51]. The seminar was open for undergraduate students. A basic interest in sustainability issues, sociological perspectives, and visual ethnography, including film technology and aesthetics, were expected. The exam for each project group of 3-5 students consisted of two elements: the production of a short movie ( $5 \mathrm{~min}$ ) as well as an accompanying scientific reflection paper (10-15 pages), in which the analyzed sustainability issue is described based on relevant scientific literature, the procedure of the visual ethnographic short film is outlined, and the potential of sensory sustainability reflected. The whole course consisted of $150 \mathrm{~h}$ workload. It ran for 14 weeks, with two hours weekly in-person, as the syllabus shows:

1. Introduction: Topic, method, way of working, goals

2. Conceptual and empirical foundation of sustainable development

3. Topics and research subjects of sustainability, politics and everyday life

4. Visual ethnography: theoretical foundations

5. Visual ethnography: methods and practice

6. Documentary filmmaking: foundations on aesthetics

7. Documentary filmmaking: foundations of technology

8. Project design (1): selection of topics and project organization

9. Project design (2): research and film strategy

10. Film production (1): field research and filming

11. Film production (2): field research and filming

12. Analysis and interpretation of film material considering scientific literature

13. Cutting and editing

14. Presentation and Résumé

The seminar took place in cooperation with the German filmmaker Jörg-Daniel Hissen, who holds extensive experience in documentary filmmaking particularly on environmental and sustainability topics [52]. His main role was to bring in theoretical and practical knowhow on film aesthetic and technical skills. The seminar was chosen by 25 students from different backgrounds including cultural studies, environmental studies, engineering, and pedagogical studies. Following the introductory session (1) and the literature-based discussion on conceptual and empirical foundation of sustainable development (session 2), a brainstorming session took place in order to generate potential topics and research subjects, and in order to spread out the scope of possibilities (session 3). Parallel to this were the next literature-based sessions on visual ethnography (session 4,5 ) and the more practical sessions on filmmaking led by Daniel Jörg Hissen (session 6,7); students were are asked to organize themselves into five groups and start thinking about potential topics of interest for their project work. In session eight and nine, the projects were concretized and designed. In these workshop sessions, the three central perspectives of the seminar-sustainability science, visual ethnography, and documentary filmmaking - were brought together. The study groups had to develop exposés entailing research topic, research question, content description including protagonists, film 
location, film scenes, and goals aimed at, as well as scientific literature search strategy. The research topics and guiding research questions were:

Group 1: Water cycle-Which potentials of sustainable water usage does the water cycle of an aquaponic system [53] have?

Group 2: Mobility choice-What motivates people to regularly use certain means of transport?

Group 3: Slow fashion-What sustainability ideals do salesman/woman and consumers have of quiddje/Vunderland (enterprise for vegan, handmade, sustainable clothes)?

Group 4: Sustainable animal farming_Does the "Bruderhahn-Initiative" [54] provide an option for more sustainable animal farming?

Group 5: Waste management-What kind of problems exist in waste disposal, and what are options for improvement?

The project groups than had four weeks (session 10-13), coached by the lecturers, for field research and filming, analysis, and interpretation of film material considering scientific literature as well as cutting and editing. In the concluding session (14), the project groups presented their findings in presentations of twenty minutes, consisting of $5 \mathrm{~min}$ film and $15 \mathrm{~min}$ presentation.

Reflecting on the seminar regarding the quest for teaching sustainable development in a more sensory way, several observations can be made. First, enabling a firm basis on theoretical and methodological key aspects of sensory sustainability science, as well as basic aesthetic and technical knowhow in filmmaking, is essential at the beginning of the seminar, in order to be able to identify suitable research subjects. Second, the development of significantly focused topics and the specification of research questions is of key importance to realize the scientific-artistic project given the limited time of a seminar. In retrospect, the topics and research questions could have been sharpened even more. The timeframe of four weeks for field research, scientific literature investigation, filming and postproduction was tight, but doable, if the students set up a well-organized division of labor, and if they were willing to invest time in this phase of the seminar. In this regard, it is important to note that the final products—short film and scientific paper-had to be handed by 15 September, which was three months after the end lecture period. For the presentation in classroom, a first version of the film and interim results on the scientific investigation were expected. Despite the considerable complexity of the experimental course, the project results of the study groups proved that the scientific-artistic approach worked. The students expressed in their reflection papers that they felt they had gained a new approach beyond established scientific methods in sustainability research, and that the visualization of materialized sustainability phenomena had sensitized in a new way the sustainability challenges and solution options. Finally, three (pre-)conditions appeared to be crucially important: There was a risk that the film projects distract students from the initial scientific goal of the enterprise. It was of utmost importance to keep aware the interactive, scientific-artistic double feature of sensory sustainability science. Therefore, the close collaboration and exchange between the involved scientists and film artist in classroom and outside classroom preparing the session was fundamental. Students needed to experience from the beginning till the end that, through the collaborative performance of the lecturers, the scientific and the artistic perspective represent two sides of the same coin of sensory sustainability science. Last, but not least, the size of the seminar matters. In our seminar, 25 students participated, this was already a lot. In order to allow for in-depth discussion and close collaboration between lectures and students to handle the complexity of this learning and doing situation, a limitation of 20 students would be helpful.

\section{Bureau of Expertise for Critical Thinking and Artistic Intervention}

In the summer term 2019, the seminar "Bureau of expertise for critical thinking and artistic intervention" was offered. This course aimed at exploring the potential of scientificartistic analysis and intervention in issues of (un)sustainable development. By the means of scientific research methods and strategies of visual arts, in specific social interventionist 
arts, new insights, and a shift in perspective of sustainability topics should be enabled. The underlying idea for this project was that (un)sustainable development is deeply anchored in oftentimes routinized, unreflected socio-material practices [55]. Meanwhile, (sustainability) science has its strength in systematic, cognitivist analysis and deriving solution options, visual arts have their power in irritating, provoking, and questioning established perceptions and practices by irrational sensory-aesthetic interventions $[56,57]$. In the seminar, both spheres should be systematically bound together for addressing selected topics and research questions in order to generate new insights as well as given an impulse into fields of practice. A basic interest in sustainability issues and visual arts were expected. The exam for each project group of 3-5 students consisted of two elements: the production of an intervention as well as an accompanying scientific reflection paper (10-15 pages), in which the analyzed sustainability issue was described based on relevant scientific literature, the procedure of the intervention was outlined and the potential of sensory sustainability reflected. The whole course consisted of $150 \mathrm{~h}$ workload. It ran for 13 weeks, with two hours weekly in-person, as the syllabus shows.

1. Introduction: Topic, method, way of working, goals

2. Conceptual and empirical foundation of sustainable development

3. Conceptual and methodological foundations of critical thinking

4. Conceptual and methodological foundations of artistic intervention

5. Research subjects (1): Arts-based methods for generation of ideas

6. Research subjects (2): Projects and study groups

7. Research strategies: scientific and artistic methods

8. Scientific-artistic research of selected topics (1)

9. Scientific-artistic research of selected topics (2)

10. Intervention strategies: scientific and artistic forms of presentation and intervention

11. Design of Intervention on selected topics

12. Intervention on selected topics

13. Synthesis and Outlook

The seminar took place in cooperation with the German visual artist Daniel Hoernemann, who holds extensive experience in artistic interventions in contexts of societal development [58]. His role was to bring in strategies of artistic investigation and intervention. Twenty students from different backgrounds including cultural studies, environmental studies, social sciences, and pedagogical studies participated. Following the introduction (1) in three literature-based sessions (2-4) foundational conceptual, empirical, and methodological insights were elaborated: basics of sustainable development; basics of critical thinking as research attitude; and basics of artistic intervention in sustainability contexts. Session five and six were organized as workshops with the aim to defining research subjects and organize the projects and study groups. The research topics and guiding research questions were:

Group 1: Traffic island-How far can perception of human-nature-borders be shifted by temporary appropriating a traffic island as living space?

Group 2: Spatial perception-To what extent can routinized use of top-down planned campus infrastructure be opened up by temporary spatial modification?

Group 3: Surveillance-How far does a surveillance intervention affect visitors at a university canteen?

Group 4: Body images-What happens, if people are confronted with (female) bodies, which do not try to fulfill dominating norms, and with the presenters themselves?

The next session (7) dealt with scientific and artistic research strategies and methods. The study groups than had two weeks' time for the scientific-artistic research of their topics (8-9). Before the background of the interim results of this investigation, in the next session, intervention strategies were discussed in class (10). Scientific and artistic forms of intervention and presentation were reflected upon (11). In the week of session twelve the 
interventions were realized. The seminar ended with a synthesis and an outlook on the potential of such a way of working for sustainable development.

Like in the previous case study, by reflecting on the seminar regarding the quest for teaching sustainable development in a more sensory and aesthetic light, several insights can be made. As observed already in the film-seminar, the literature-based discussions of the first sessions as well as the acquaintance of artistic strategies of research and intervention are of utmost importance. Meanwhile, although undergraduate students of the third or fourth semester, already, to some extent, possess a scientific attitude and fundamental understanding of conceptual and methodological procedure, the way of working in visual arts is largely unknown territory for them. In fact, it is quite challenging, because in artistic practices dimensions such as irrationality, uniqueness, sensing, imagination are central, which differ significantly from the systematic, rational, cognitivist world view of science. Particularly important in this regard was the arts-based workshop on generating ideas for the student projects, in which the students went creatively beyond the spectrum of "usual" sustainability topics. Looking at the selected topics and research questions, however, it can be stated that a more guided process could have helped to realize projects, which more explicitly contribute to sustainable development. Project three and four, for example, are - at best-located at the margins of social sustainability. Comparable to the experience of the film-seminar the timeframe for the practical scientific-artistic research and the design of the investigation was ambitious and demanded student commitment and efficient division of labor in the study groups. The advantage of the quite tight timeframe was an overall goal-oriented and intensive engagement of the students. Moreover, it is important to note that the final products - documentation of the intervention and scientific reflection paper-had to be handed in by 15th September, which was three months after the end of the lecture period. Although the students were confronted with the unchartered territory of visual arts practice, and a generally complex seminar setting, the resulting interventions showed a high level of creativity. Compared with this the required scientific analysis of the respective topics could have been elaborated a somewhat more. It seems that students were more motivated to engage with the arts-based part in the seminar. Even more attention and guidance on the scientific part of the twosided scientific-artistic research process could have been necessary. Despite the intellectually challenging and labor-intensive seminar the discoursive seminar feedback of students was positive. Especially the relatively high degree of "allowed and demanded creativity" was felt as enriching, and allowed for a more sensory access to sustainable development. Summarizing the experiences of this experimental course, it can be stated that similar to the film-seminar two challenges stand out: First, to keep students' awareness during the seminar, a systematic, interrelated scientific-artistic procedure was important for sensory-aesthetic sustainability science. There is apparently a risk of slipping more towards the artistic side of the approach. Second, the careful definition of topics and research questions in order to allow for appropriate projects given the limited time of a seminar. The existing tension between open-minded, creative search for research subjects and content-related (sustainability issues) as well as time-related (seminar with $150 \mathrm{~h}$ workload) restrictions need to addressed proactively.

\section{Sound of Sustainability}

In the summer term 2020, the seminar "Sound of Sustainability" was offered. After having explored in the previous seminars the potential of visual ethnography and the interventionist arts practice for sensory sustainability research, this seminar was focused on the acoustic dimension. Based on recent discussions around the "acoustic turn" [59], which point out the oftentimes "invisible" relevance of the "auditive society", manifested in developments such as popularity of audio books, Spotify, sonification of scientific data, soundscapes, sound design up to noise pollution, the seminar aimed at grasping sounds of (un)sustainability. Like in the other two seminars, the basic approach again was to connect the scientific analysis with strategies of arts-based approaches, in this case of sound art. Accordingly, a basic interest in sustainability issues and visual arts were expected. The exam for each study group of 3-5 students consisted of two elements: the production of a soundclip well as an accompanying scientific reflection paper (10-15 pages), in which 
the analyzed sustainability issue is described based on relevant scientific literature, the procedure of the sound recording and design is outlined and the potential of sensory sustainability reflected. The whole course consisted of $150 \mathrm{~h}$ workload. Due to the Coronavirus pandemic, the course took place entirely virtual employing a video conference system. It ran for 13 weeks, with two hours weekly in-person, as the syllabus shows:

1. Introduction: Topic, method, way of working, goals

2. Conceptual and empirical foundation of sustainable development

3. Sensory sustainability science: conceptual and methodological foundations

4. Sensory (acoustic) ethnography: conceptual and methodological foundations

5. Noises, tones, sounds: conceptual and empirical foundations of sound art

6. Research subjects: topic identification and organization of study groups

7. Ethnographic and arts-based analysis of selected topics

8. Ethnographic and arts-based analysis of selected topics

9. Sound art: design strategies and techniques

10. Ethnographic and arts-based sound design of selected topics

11. Digital presentation of group work (1)

12. Digital presentation of group work (2)

13. Synthesis and outlook

The seminar took place in cooperation with sound artist Kaspar König from Zurich University of the Arts [60]. Analogous to the previous sensory sustainability seminars, he brought in strategies of investigation and design of sound art. I contributed the perspective of (sensory) sustainability science. Fifteen students from environmental science, cultural studies, psychology, and business administration participated. The general structure of the seminar is oriented towards the preceding seminar experiences. After the introductory session (1), four literature-based sessions were scheduled to get across the foundations of sustainable development, sensory sustainability science, sensory (auditive) ethnography, and sound art (2-5). Session sixth was set up as workshop for the identification of topics and the organization of study groups.

Group 1: Lifecycle of bread-By how far can the complex and invisible value chain of bread from corn to kitchen be made audible?

Group 2: Conventional vs. organic agriculture-Can we hear differences between conventional and organic agriculture?

Group 3: Ambient sounds and wellbeing-Which ambient sounds are registered by participatory recording and how are the related to wellbeing?

Group 4: Artificial nature sounds-To what extent can nature sounds be artificially designed?

The following two weeks the study groups had time for field research (sound recording) and scientific analysis of the topics (7-8). In the next session (9), basic design strategies and techniques of sound art were introduced, in order to enable the students to create a sensory and aesthetic interesting sound clip (10). The seminar ended with two sessions (11-12), where the four groups presented their (preliminary) sound clips and scientific findings, and a concluding session (13).

Reflecting on the seminar, similar observations to the previous courses can be made. Even though the artistic field differed, the experiences and challenges are comparable especially regarding the film-making experiment. Sound art and auditive ethnography might be even more unusual for students to engage with and make use of in the context of sustainable development. Thus, the sessions on providing ethnographic and artsbased basics regarding sound recording and design were particularly challenging but at the same time "eye-opening" respectively "ear-opening" for the participants. Inspired by the overview of the potential of sound art, the students showed a high degree of creativity and engagement as well in defining topics and research questions as in the following field recording. In order to better fulfill the scientific analysis of the topic more attention was given to this aspect by the co-teachers during the whole seminar. The 
biggest challenge of this seminar obviously was the acquisition of sound art strategies and techniques for creating the soundclip. Given the substantial complexity in approaching the audible world of noises and sounds from an artistic point of view, it is no surprise that compromises concerning the aesthetics of the final product need to be accepted. However, the study groups managed in due time to produce digital presentations including meaningful (preliminary) sound clips accompanied by relevant scientific insights on the selected topics and handed in enhanced final products by the end of the exam deadline in mid-September. Next to some analogous experiences as in the other two seminars, such as finding a well narrowed topic and focused research question or keeping attention to the double-sided scientific-artistic procedure, it can be finally stated that to some degree, limited technological and aesthetical sound art skills might be unavoidable and therefor condoned.

Before the backdrop of the descriptive reflection of the three experimental seminars, some overarching insights on sensory-aesthetic teaching on sustainable development can be derived:

- Scientific and artistic expertise need to be provided continuously during the seminar.

- Openness and a collaborative relationship between (co-)teachers and students need to be nurtured.

- The course needs to be well designed regarding the double-sided scientific-artistic approach in order to not lose track of the scientific analysis

- A sound theoretical and methodological basis regarding the field of research at hand is essential.

- The potential tension between creative definition of topics and research questions and an adequate scope given the limited time and resources of a seminar need to be managed.

- Sufficient time should be calculated for field research, intervention, and the arts-based creation of products.

- The evaluation of the study projects needs to reflect the scientific and arts-based approach. The aspect of aesthetic quality must be seen in the context of the goal of sensory sustainability science; it ought not be compared with "l'art pour l'art".

The experiences with the experimental courses of teaching sustainable development more sensory and artfully are overall encouraging. Not least because students have acknowledged in the discoursive feedback at the end of the seminars the opportunity to live out creativity and experience new approaches for engaging with sustainability issues. In face of this reflections of practical teaching experiences and the theoretical-conceptual considerations discussed at the beginning of this article the concluding section gives an outlook on potentials and challenges.

\section{Outlook: Potentials and Challenges for Teaching Sustainable Development Sensory and Artfully}

At the beginning of this article, we argued that despite short-term political pressures such as the Coronavirus pandemic, populism, or geopolitical tensions, longer-term unsustainable developments remain a major threat for the future of mankind. In these challenging situations, the UN-Transformation Agenda 2030 represents the key reference point for the grand idea of sustainable development. It reminds us that more and new efforts are required in all social spheres. The educational sector has been an important target in the discourse and practice on sustainable development since 1992 and, consequently, it is prominently represented within the global sustainable development goals (SDG 4). Over the past three decades, impressive innovations and progress have been made under the umbrella of education for sustainable development. However, with regard to theoretical approaches that point to the dimension of multisensorial conditions of human existence through concepts such as "resonance" or "atmosphere", this article argued for a more sensory and artfully teaching of sustainable development in order to raise students' awareness for multisensory reality and develop skills to engage creatively for well-being- 
oriented sustainability transformation. The engagement with multisensorial dimensions and the connected (embodied) imagination requires a more explicit, systematic seizing of sensory-aesthetic approaches, such as visual, auditive, or performative approaches employed in the courses. It is argued that the complementary procedure employed in the seminars, connecting scientific, and artistic perspectives, is principally possible. Thus, the cognitive-analytical perspective of science can be combined with the sensory-aesthetic experience of (diverse) arts practices. In this regard, the experimental courses provide a first attempt to transpose the fundamental considerations of theoretical-sensory studies into curriculum design. A cursory discoursive seminar feedback of the participating students at the end of the three courses hint in the direction; in so far as, the courses have the potential to open up new perspectives, have stimulated student's creativity, empowered them to think critically beyond the limitations of existing methods and topics, and sensitized them for experiences transgressing the cognitive-rational. However, given that the focus of this article is on delivering a dense description of experimental courses designed for artful and sensory sustainability teaching and not of analyzing student-centered learning outcomes, the impact of these kinds of courses need to be studied systematically in further studies. Nevertheless, the explorative experiment suggests that the proposed approach might contribute in novel ways to key areas in education for sustainable development. With regard to the five central dimensions of the UNESCO artful and sensory approach, teaching might contribute especially to the dimensions "learning content (integrating critical issues)" and "societal transformation (transform themselves and society)" [35]. Concerning the first, the descriptive analysis and qualitative reflection of the experimental courses suggest that new, unusual perspectives can be generated, which may foster different access to established and new issues. Concerning the latter, the artful and sensory approach may help to transform the learners and - on the long run—affect society, by experiencing sensory and aesthetic dimensions of topics. Beyond these potential effects, a more conceptual contribution may be derived from the experimental courses as well. Given the central role of key competencies in ESD as outlined above (Wiek et al. 2011), it might be argued that the approach of sensory and artful sustainability teaching presented in this article may represent a new competence next to systems thinking, anticipatory competence, normative competence, strategic competence, interpersonal competence, which could be called sensory-aesthetic competence. The integration of this competence into the general framework of "key competences" would do justice to the academic debate in interdisciplinary sensory studies on the multisensoriality of human existence and push forward the specific potential of arts-based approaches for (multidimensional) experiential learning in this context.

Despite the interesting possibilities of this approach, some challenges need to be taken seriously nevertheless. If the point of view of this article is that it is to be shared, then it would be desirable to have more systematic trials, evaluations, and didactical developments to safeguard a good teaching practice for sensory-aesthetic competence. Specific attention in this context ought to be given to the reflection of quality criteria for sensory and artfully approaches. As discussed in literature on arts-based methods as well as on creative and sensory ethnography. Traditional scientific evaluation criteria are as misleading as assessment mechanisms in arts. It seems to be necessary to use a tailored framework for scientific-artistic formats. Closely related to this aspect is the question of who is giving the course. In the described cases, the decision was made to invite artists for collaborative teaching. This worked well, especially because the artists could support the students' projects with their hands on technical and aesthetic expertise. However, given the widespread limited resources for co-teaching, it would also be possible to conduct such a seminar with inviting artists only to specific sessions. Moreover, with some curiosity and training, it should be possible to develop adequate arts-based skills to realize professionally such a seminar without external input by artistic lecturers. Finally, the biggest challenge might be, the institutional (pre-)conditions for including artistic approaches into sustainability curricula. Not every (sustainability) scientist will immediately welcome the artistic and-from their view-unscientific approach. Engaged exchanges of views and ideas will 
be necessary to rediscover the insight whereby science and arts represent two sides of the same coin of understanding and constructing the world. Sustainable development as an open-ended, participative search, and learning and creative process can only profit from students, which are cognitive-rational and sensory-aesthetic competent.

Funding: This research received no external funding.

Institutional Review Board Statement: Not applicable.

Informed Consent Statement: Informed consent was obtained from all subjects involved in the study. Data Availability Statement: Not applicable.

Conflicts of Interest: The authors declare no conflict of interest.

\section{References}

1. United Nations. Department of Economic and Social Affairs. Sustainable Development. Transforming our World: The 2030 Agenda für Sustainable Development. Available online: https://sustainabledevelopment.un.org/post2015/ transformingourworld (accessed on 1 December 2021).

2. Sustainable Development Goals. Sustainable Development Goals Report. Available online: https://www.un.org/ sustainabledevelopment/progress-report (accessed on 1 December 2021).

3. Heinrichs, H. Strengthening Sensory Sustainability Science-Theoretical and Methodological Considerations. Sustainability 2019, 11, 769. [CrossRef]

4. Heinrichs, H.; Martens, P.; Michelsen, G.; Wiek, A. (Eds.) Sustainability Science: An Introduction; Springer: Dordrecht, The Netherlands, 2016; ISBN 978-9-401-77241-9.

5. Sachs, J. The Age of Sustainable Development; Columbia University Press: New York, NY, USA, 2015.

6. Huan, Q. Eco-Sociolism as Politics. Rebuilding the Basis of Our Modern Civilization; Springer: Dordrecht, The Netherlands, 2014.

7. Rauschmayer, F.; Bauler, T.; Schäpke, N. Towards a thick understanding of sustainability transitions-Linking transition management, capabilities and social practices. Ecol. Econ. 2015, 109, 211-221. [CrossRef]

8. Kates, R.W. What kind of a science is sustainability science? Proc. Natl. Acad. Sci. USA 2011, 108, 19449-19450. [CrossRef] [PubMed]

9. Vries, B.J.M. Sustainability Science; Cambridge University Press: Cambridge, UK, 2013.

10. Lang, D.J.; Wiek, A.; Bergmann, M.; Stauffacher, M.; Martens, P.; Moll, P.; Swilling, M.; Thomas, C.J. Transdisciplinary research in sustainability science: Practice, principles, and challenges. Sustain. Sci. 2012, 7, 25-43. [CrossRef]

11. Howes, D. The Expanding Field of Sensory Studies. 2013. Available online: www.sensorystudies.org (accessed on 1 December 2021).

12. Marx, K. Das Kapital: Kritik der Politischen Ökonomie, Bd. 1 Der Produktionsprozess des Kapitals, 33rd ed.; Dietz: Berlin, Germany, 1989; ISBN 3-320-00262-7.

13. Freud, S. Das Ich und das Es: Metapsychologische Schriften; Fischer: Frankfurt am Main, Germany, 2009; ISBN 978-3-59690205-7.

14. Simmel, G.; Soziologie der Sinne. Die Neue Rundschau; Soziologisches Institut der Universität Zürich: Zürich, Switzerland, 1907; Volume 18, pp. 1025-1036.

15. Plessner, H. Anthropologie der Sinne-Gesammelte Schriften; Suhrkamp: Frankfurt am Main, Germany, 1980; ISBN 3-51806524-6.

16. Merleau-Ponty, M. Phänomenologie der Wahrnehmung; Walter de Gruyter: Berlin, Germany, 1965; ISBN 978-3-110-06884-9.

17. Böhme, G. Atmosphäre—Essays zur neuen Ästhetik; Suhrkamp Verlag: Berlin, Germany, 2017.

18. Reckwitz, A. Toward a theory of social practices: A development in culturalist theorizing. Eur. J. Soc. Theory 2002, 5, 243-264. [CrossRef]

19. Haraway, D. Ein Manifest für Cyborgs. Feminismus im Streit mit den Technowissenschaften. In Die Neuerfindung der Natur. Primaten, Cyborgs und Frauen; Haraway, D., Ed.; Campus: Frankfurt am Main, Germany, 1995; pp. 33-72, ISBN 3-593-35241-9.

20. Rosa, H. Resonanz. Eine Soziologie der Weltbeziehung; Suhrkamp: Frankfurt am Main, Germany, 2018.

21. Pink, S. Doing Sensory Ethnography; Sage Publications: London, UK, 2015.

22. Elliott, D.; Culhane, D. (Eds.) A Different Kind of Ethnography_Imaginative Practices and Creative Methodologies; University of Toronto Press: North York, OT, Canada, 2017; ISBN 978-1-4426-2662-0.

23. Leavy, P. Method Meets Art: Arts-Based Research Practice; Guilford Press: New York, NY, USA, 2015.

24. Pink, S. Sense and sustainability: The case of the Slow City movement. Local Environ. Int. J. Justice Sustain. 2008, 13, 95-106. [CrossRef]

25. Kagan, S. Art and Sustainability: Connecting Patterns for a Culture of Complexity; Transcript Verlag: Bielefeld, Germany, 2011.

26. Galafassi, D. The Transformative Imagination: Re-Imagining the World Towards Sustainability; Stockholm University: Stockholm, Sweden, 2018.

27. Heinrichs, H. Artful sustainability governance-Foundational considerations on sensory-informed policymaking for sustainable development. Sustain. Dev. 2020, 28, 791-799. [CrossRef] 
28. Aboytes, J.G.R.; Barth, M. Transformative learning in the field of sustainability: A systematic literature review (1999-2019). Int. J. Sustain. High. Educ. 2020, 21, 993-1013. [CrossRef]

29. Weiss, M.; Barth, M. Global research landscape of sustainability curricula implementation in higher education. Int. J. Sustain. High. Educ. 2019, 20, 570-589. [CrossRef]

30. Wals, A.E.J.; Kieft, G. Education for Sustainable Development: Research Overview; Swedish International Development Agency: Stockholm, Sweden, 2010.

31. Jones, P.; Selby, D.; Sterling, S. Sustainability Education-Perspectives and Practice across Higher Education; Earthscan: London, UK, 2010.

32. Sustainable Development Goals. Knowledge Platform. Agenda 21. Available online: https://sustainabledevelopment.un.org/ outcomedocuments/agenda21 (accessed on 1 December 2021).

33. Unesco. UN Decade of ESD. Available online: https://en.unesco.org/themes/education-sustainable-development/what-is-esd/ un-decade-of-esd (accessed on 1 December 2021).

34. Unesco. Global Action Programme on Education for Sustainable Development (2015-2019). Available online: https://en.unesco. org/globalactionprogrammeoneducation (accessed on 1 December 2021).

35. Unesco. What is Education for Sustainable Development? Available online: https://en.unesco.org/themes/educationsustainable-development/what-is-esd (accessed on 1 December 2021).

36. Barth, M. Teaching and Learning in Sustainability Science. In Sustainability Science—An Introduction; Heinrichs, H., Martens, P., Michelsen, G., Wiek, A., Eds.; Springer: Dordrecht, The Netherlands, 2016.

37. Barth, M.; Godemann, J.; Rieckmann, M.; Stoltenberg, U. Developing key competencies for sustainable development in higher education. Int. J. Sustain. High. Educ. 2007, 8, 416-430. [CrossRef]

38. Wiek, A.; Withycombe, L.; Redman, C.L. Key competencies in sustainability: A reference framework for academic program development. Sustain. Sci. 2011, 6, 203-218. [CrossRef]

39. Bagely, C.E.; Sulkowski, A.J.; Nelson, J.S.; Waddock, S.; Shrivastava, P.A. Path to Developing More Insightful Business School Graduates: A Systems-Based, Experimental Approach to Integrating Law, Strategy, and Sustainability. Acad. Manag. Learn. Educ. 2020, 19, 541-568. [CrossRef]

40. Sulkowski, A.J.; Kowalczyk, W.; Ahrendsen, B.L.; Kowalski, R.; Majewski, E. Enhancing sustainability education through experiential learning of sustainability reporting. Int. J. Sustain. High. Educ. 2020, 21, 1233-1247. [CrossRef]

41. Ward, K.S. Creative Arts-Based Pedagogies in Early Childhood Education for Sustainability (EfS). Aust. J. Environ. Educ. 2013, 29, 165-181. [CrossRef]

42. O'Gorman, L. The Arts and education for sustainability. In Research in Early Childhood Education for Sustainability—International Perspectives and Provocations; Davis, J., Elliott, S., Eds.; Routledge: New York, NY, USA, 2014.

43. Lauesen, L.M. The Role of the (Governance of the) Arts in Cultural Sustainability: A Case Study of Music. In Accountability and Social Responsibility: International Perspectives (Developments in Corporate Governance and Responsibility; Emerald Group Publishing Limited: Bingley, UK, 2016; Volume 9, pp. 49-74. [CrossRef]

44. Jónsdóttir, Á.B. Artistic Actions for Sustainability: Potential of Art in Education for Sustainability (Doktorsritgerð); University of Lapland: Rovaniemi, Finland, 2017.

45. Österlind, E. Drama in higher education for sustainability: Work-based learning through fiction? In Higher Education, Skills and Work-Based Learning; Emerald Publishing Limited: Bingley, UK, 2018; Volume 8, pp. 337-352. [CrossRef]

46. Ostergaard, E. Music and sustainability education-A contradiction? Acta Didact. Nor. 2019, 13, 2-20. [CrossRef]

47. Hunter, M.A.; Aprill, A.; Hill, A.; Emery, S. Education, Arts and Sustainability. Emerging Practice for a Changing World; Springer: Singapore, 2018.

48. Wall, T.; Österlind, E.; Fries, J. Arts-Based Approaches for Sustainability. In Encyclopedia of Sustainability in Higher Education; Filho, L.W., Ed.; Springer: Cham, Switzerland, 2019. [CrossRef]

49. Wall, T.; Österlind, E.; Fries, J. Art-Based Teaching on Sustainable Development. In Encyclopedia of Sustainability in Higher Education; Filho, L.W., Ed.; Springer: Cham, Switzerland, 2019. [CrossRef]

50. Lindgren, S. Digital Media and Society; SAGE: London, UK, 2017.

51. Pink, S. Doing Visual Ethnography; SAGE: London, UK, 2013.

52. Riverside Film Jörg Daniel Hissen. Christo \& Jeanne-Claude. Available online: http://www.riversidefilm.de (accessed on 1 December 2021).

53. Wikipedia. Aquaponics. Available online: https://en.wikipedia.org/wiki/Aquaponics (accessed on 1 December 2021).

54. Wikipedia. Chick culling. Available online: https://en.wikipedia.org/wiki/Chick_culling (accessed on 1 December 2021).

55. Brand, K.W. Social practices and sustainable consumption: Benefits and limitations of a new theoretical approach. In Environmental Sociology_European Perspectives and Interdisciplinary Challenges; Gross, M., Heinrichs, H., Eds.; Springer: Dordrecht, The Netherlands, 2010; pp. 217-236.

56. Mouffe, C. Artistic Activism and Agonistic Spaces. Art Res. J. Ideas Contexts Methods 2007, 1, 1-5.

57. Antal, A.B. When Arts Enter Organizational Spaces: Implications for Organizational Learning. In Learning Organizations. Knowledge and Space (Klaus Tschira Symposia); Antal, B.A., Meusburger, P., Suarsana, L., Eds.; Springer: Dordrecht, The Netherlands, 2013; Volume 6. [CrossRef] 
58. Hoernemann \& Walbrodt. Available online: http://www.communityartworks.de (accessed on 1 December 2021).

59. Meyer, P.M. Accoustic Turn; Wilhelm Fink: München, Germany, 2008.

60. Zurich University of the Arts. Kaspar König. Available online: https://www.zhdk.ch/en/person/187661 (accessed on 1 December 2021). 